\title{
High Incidence and Prevalence of Drug-Related Movement Disorders in Young Patients With Psychotic Disorders
}

Citation for published version (APA):

Mentzel, T. Q., Lieverse, R., Bloemen, O., Viechtbauer, W., Genetic Risk and Outcome of Psychosis (GROUP) Investigators, \& van Harten, P. N. (2017). High Incidence and Prevalence of Drug-Related Movement Disorders in Young Patients With Psychotic Disorders. Journal of Clinical Psychopharmacology, 37(2), 231-238. https://doi.org/10.1097/JCP.0000000000000666

Document status and date:

Published: 01/04/2017

DOI:

10.1097/JCP.0000000000000666

Document Version:

Publisher's PDF, also known as Version of record

Document license:

Taverne

Please check the document version of this publication:

- A submitted manuscript is the version of the article upon submission and before peer-review. There can be important differences between the submitted version and the official published version of record.

People interested in the research are advised to contact the author for the final version of the publication, or visit the DOI to the publisher's website.

- The final author version and the galley proof are versions of the publication after peer review.

- The final published version features the final layout of the paper including the volume, issue and page numbers.

Link to publication

\footnotetext{
General rights rights.

- You may freely distribute the URL identifying the publication in the public portal. please follow below link for the End User Agreement:

www.umlib.nl/taverne-license

Take down policy

If you believe that this document breaches copyright please contact us at:

repository@maastrichtuniversity.nl

providing details and we will investigate your claim.
}

Copyright and moral rights for the publications made accessible in the public portal are retained by the authors and/or other copyright owners and it is a condition of accessing publications that users recognise and abide by the legal requirements associated with these

- Users may download and print one copy of any publication from the public portal for the purpose of private study or research.

- You may not further distribute the material or use it for any profit-making activity or commercial gain

If the publication is distributed under the terms of Article $25 \mathrm{fa}$ of the Dutch Copyright Act, indicated by the "Taverne" license above, 


\title{
High Incidence and Prevalence of Drug-Related Movement Disorders in Young Patients With Psychotic Disorders
}

\author{
Thierry Q. Mentzel, MSc, *† Ritsaert Lieverse, MD, PhD, $\uparrow$ Oswald Bloemen, MD, PhD, *† \\ Wolfgang Viechtbauer, PhD, $\dagger$ Peter $N$. van Harten, $M D, P h D$, *广 and The Genetic \\ Risk and Outcome of Psychosis (GROUP) Investigators
}

\begin{abstract}
:
Background: Drug-related movement disorders (DRMDs) reduce quality of life and contribute to medication noncompliance of patients with psychotic disorders. Little is known about the epidemiology of DRMDs in relatively young patients a few years after onset of psychosis. This is an important period to study, as the impact of the antipsychotic treatment on the long-term potentiation of the neural pathways associated with psychotic disorders and DRMDs is still minimal. This study investigated the prevalence, incidence, persistence, and clinical correlates of DRMDs in patients during their first years after disease onset.

Methods: The Genetic Risk and Outcome of Psychosis study is a longitudinal study of 1120 relatively young patients with nonaffective psychosis and a mean age and illness duration of 27 and 4 years, respectively. The following drug-related movement disorders were assessed at baseline and at
\end{abstract}

From the *Innova, GGZ Centraal, Amersfoort; and $\dagger$ Department of Psychiatry and Neuropsychology, Maastricht University, Maastricht, the Netherlands.

Received July 11, 2016; accepted after revision December 20, 2016.

Reprints: Thierry Q. Mentzel, MSc, Innova, GGZ Centraal, Zon \& Schild, De Veste, 3800DB Amersfoort, the Netherlands (e-mail: t.q.mentzel@gmail.com).

The Genetic Risk and Outcome of Psychosis Investigators include the following: Richard Bruggeman, MD, PhD, Department of Psychiatry, University Medical Center Groningen, University of Groningen; Wiepke Cahn, MD, PhD, Department of Psychiatry, Rudolf Magnus Institute of Neuroscience, University Medical Center Utrecht; Lieuwe de Haan, MD, $\mathrm{PhD}$, Department of Psychiatry, Academic Medical Center, University of Amsterdam; René S. Kahn, MD, PhD, Department of Psychiatry, Rudolf Magnus Institute of Neuroscience, University Medical Center Utrecht, Utrecht, the Netherlands; Carin Meijer, PhD, Department of Psychiatry, Academic Medical Center, University of Amsterdam; Inez Myin-Germeys, PhD, South Limburg Mental Health Research and Teaching Network, EURON, Maastricht University Medical Center; Jim van Os, MD, PhD, South Limburg Mental Health Research and Teaching Network, EURON, Maastricht University Medical Center, Maastricht, the Netherlands, and King's College London, King's Health Partners, Department of Psychosis Studies, Institute of Psychiatry, London, England; and Agna Bartels, PhD, Department of Psychiatry, University Medical Center Groningen, University of Groningen, Groningen, the Netherlands.

Funding: The infrastructure of the GROUP study was supported by the Geestkracht programme of the Dutch Health Research Council (ZON-MW, grant number 10-000-1001), and matching funds from participating pharmaceutical companies (Lundbeck, AstraZeneca, Eli Lilly, and Janssen Cilag) and universities and mental health care organizations (Amsterdam: Academic Psychiatric Centre of the Academic Medical Center and the mental health institutions GGZ Ingeest, Arkin, Dijk en Duin, GGZ Rivierduinen, Erasmus Medical Centre, and GGZ Noord Holland Noord. Maastricht: Maastricht University Medical Centre and the mental health institutions GGZ Eindhoven en de kempen, GGZ Breburg, GGZ Oost-Brabant, Vincent van Gogh voor Geestelijke Gezondheid, Mondriaan Zorggroep, Prins Clauscentrum Sittard, RIAGG Roermond, Universitair Centrum Sint-Jozef Kortenberg, CAPRI University of Antwerp, PC Ziekeren Sint-Truiden, PZ Sancta Maria Sint-Truiden, GGZ Overpelt, and OPZ Rekem. Groningen: University Medical Center Groningen and the mental health institutions Lentis, GGZ Friesland, GGZ Drenthe, Dimence, Mediant, GGNet Warnsveld, Yulius Dordrecht, and Parnassia psycho-medical center (The Hague). Utrecht: University Medical Center Utrecht and the mental health institutions Altrecht, GGZ Centraal, Riagg Amersfoort, and Delta)

Copyright (C) 2017 Wolters Kluwer Health, Inc. All rights reserved.

ISSN: 0271-0749

DOI: 10.1097/JCP.00000000000000666 the 3-year follow-up: parkinsonism, akathisia, tardive dyskinesia, and tardive dystonia. We determined prevalence, incidence, and persistence and investigated clinical correlates at and over the baseline and follow-up assessment. Results: Patients' mean age and illness duration at baseline were 27.1 and 4.3 years, respectively. In 4 patients, 1 developed a DRMD over the 3 -year study period. Prevalence, incidence, and persistence rates were highest for parkinsonism $(32 \%, 21 \%$, and $53 \%)$ followed by akathisia $(9 \%, 5 \%$, and $17 \%)$ and tardive dyskinesia $(4 \%, 3 \%$, and $20 \%)$. Significant associations were found between DRMDs and the patients' age, IQ, and psychopathology. Conclusions: The prevalence, persistence, and incidence of DRMDs in this sample were high despite the relatively young age, recent onset of the disorder, and treatment primarily with second-generation antipsychotics. These findings emphasize that screening, diagnosis, and treatment of DRMDs are still important.

Key Words: extrapyramidal symptoms, movement disorders, epidemiology

(J Clin Psychopharmacol 2017;37: 231-238)

$\mathrm{D}$ rug-related movement disorders (DRMDs) are one of the main drawbacks of antipsychotic treatment as they often reduce quality of life $^{1}$ and can contribute to medication noncompliance. ${ }^{2}$ Drug-related movement disorders are usually divided in early- and late-onset disorders. Early-onset disorders such as parkinsonism (tremor, rigidity, and bradykinesia) and akathisia develop after a relatively short period of antipsychotic treatment, whereas late-onset disorders such as tardive dyskinesia and dystonia develop after months, years, or decades of antipsychotic treatment. With the introduction of second-generation antipsychotics (SGAs), a substantial drop in the incidence of DRMDs was expected as they have a lower DRMD risk profile than firstgeneration antipsychotics (FGAs). ${ }^{3-5}$

Many studies have reported prevalence rates of DRMDs and some incidence rates, reporting high rates especially for patients treated with FGAs. ${ }^{3,46-8}$ Typically, these studies investigated patients on long-term antipsychotic treatment, often with a history of both FGA and SGA treatment. In comparison, the incidence and prevalence rates of DRMDs during the first years of antipsychotic treatment are relatively understudied, ${ }^{5}$ especially for SGA treatment. The European First-Episode Schizophrenia Trial (EUFEST) recently studied a large population over their first years of treatment $^{8,9}$ (age, $26 \pm 6$ years; illness duration, $<2$ years). They reported remarkably high DRMD prevalence rates, as high as $34 \%$ for FGAs and $28 \%$ for SGAs. ${ }^{8}$ In contrast, in a somewhat smaller and younger population (age, $20 \pm 2$; illness duration, $4 \pm 2$ ), Gebhardt et $\mathrm{al}^{5}$ reported much lower prevalence rates of $1.1 \%$ to $5.4 \%$, although subclinical signs of DRMDs were found in $39.8 \%$ of their study population. Therefore, further research is warranted, as in addition to these conflicting results, neither of these studies investigated DRMD incidence and persistence rates.

The Genetic Risk and Outcome of Psychosis (GROUP) study is a prospective study following a naturalistic design that investigated a large, relatively young (age, $27 \pm 7$ years; illness duration, 
$4 \pm 4$ years) cohort during 3 years of antipsychotic treatment on a wide range of clinical outcomes including DRMDs. Therefore, this sample is ideal for studying the incidence, prevalence, and persistence rates of DRMDs relatively early in the onset of the psychotic disorder with limited confounding by prior treatment. ${ }^{10}$ We hypothesized that the prevalence rates of DRMDs in the GROUP study would lie between the low rates reported by Gebhardt et al and the high rates found in EUFEST by Kahn et al. Second, to gain a better insight in the risks for developing DRMDs, we performed an explorative analysis of a wide range of potential clinical correlates for DRMDs.

\section{METHODS}

\section{Subjects}

The GROUP study is a multicenter cohort study performed in the Netherlands and Belgium. The objective of the GROUP study was to investigate how the variation in expression and course of nonaffective psychotic disorders relates to genetic and nongenetic factors in patients, their family members, and unrelated controls. Clinicians working in the participating academic centers and nearby psychosis departments identified eligible inand outpatients being treated a nonaffective psychotic disorder and asked them for their informed consent. The full cohort consisted of 1120 patients with nonaffective psychotic disorders, their family members (1057 siblings and 919 parents), and 590 unrelated controls. ${ }^{11}$ Korver et $\mathrm{al}^{10}$ described the details of the GROUP project extensively.

Among the GROUP study's cohort, this study investigated patients (i) with a Diagnostic and Statistical Manual of Mental Disorders, Fourth Edition (DSM-IV) diagnoses of schizophrenia and related disorders (DSM-IV 295.x) or other psychotic disorders (DSM-IV 297.x/298.x), ${ }^{11}$ (ii) on antipsychotic treatment, and (iii) who completed a DRMD assessment at baseline or follow-up.

\section{Measures}

The GROUP study is a prospective and naturalistic study of patients' clinical outcomes; these outcomes were assessed at baseline and at 3-year follow-up. The 3-year interval is a compromise between the need of a long follow-up to investigate outcome of psychosis and the need of shorter intervals to detect fluctuations in clinical outcomes. To prevent fatigue, assessments were recorded in 2 separate 2-hour sessions within a week from each other. Because of the large size of the cohort, many raters were recruited. All raters followed a 3-day workshop and bimonthly follow-up training sessions. Assessments included general demographics such as age and sex and clinical outcomes related to DRMDs and psychosis. Psychotic disorders were diagnosed with the Comprehensive Assessment of Symptoms and History ${ }^{12}$ and the Schedules for Clinical Assessment for Neuropsychiatry 2.1. ${ }^{13}$ Psychopathology was assessed with the Positive and Negative Symptom Scale (PANSS).${ }^{14}$ The IQ was assessed with the third edition of the Wechsler Adult Intelligence Scale (WAIS-III). ${ }^{15}$ These scales were administered at baseline and at follow-up in addition to the DRMD scales listed below. The patients' current prescription of antipsychotic medication(s) was registered at baseline and follow-up interviews, that is, type (FGA/SGA/both), method of administration (oral/depot), and dose. Because patients were prescribed different antipsychotics, their doses could not be compared directly. Daily defined doses (DDDs) describe the equivalent doses of many antipsychotics; these equivalents are assigned and reviewed by researchers of the World Health Organization. Thus, converting the dose(s) of each patient's prescribed antipsychotic(s) to his or her total DDDs allowed us to investigate the overall effect of antipsychotic dose on DRMDs. Prescription of anticholinergic medication(s) was also registered.

\section{Parkinsonism (Rest Tremor, Rigidity, and Bradykinesia)}

Parkinsonism was assessed with the Unified Parkinson's Disease Rating Scale (UPDRS) Part III. ${ }^{16}$ This scale consists of 27 items (range, $0-4$ ) and covers the 3 subdomains of parkinsonism: rest tremor ( 5 items), rigidity ( 5 items), and bradykinesia (9 items). Clinical parkinsonism was defined as at least (i) a "mild" score on the tremor or rigidity items, (ii) a "moderate" score on the other items, or (iii) a "mild" score on 2 or more of the other items. ${ }^{4}$ Clinical rest tremor, rigidity, and bradykinesia were, respectively, defined as scoring a mild score or more on the rest tremor items, at least a mild score on the rigidity items, and at least a moderate score or 2 mild scores on the bradykinesia items.

\section{Akathisia}

Akathisia was assessed with the Barnes Akathisia Rating Scale (BARS) ${ }^{17}$ Clinical akathisia was defined as at least a mild score on the "global clinical assessment" item ${ }^{17}$ (range, 0-5).

\section{Tardive Dyskinesia}

Tardive dyskinesia was assessed with the first 7 items of the Abnormal Involuntary Movement Scale (AIMS) ${ }^{18}$ (range, $0-4)$. Clinical tardive dyskinesia was defined with the Schooler and Kane criteria, that is, at least a moderate score or at least 2 mild scores.

\section{Tardive Dystonia}

Severity of tardive dystonia was assessed with a single item (range, $0-4$ ) added to the BARS. ${ }^{10}$ Clinical tardive dystonia was defined as a mild score or higher. ${ }^{19}$

\section{Statistical Analysis}

STATA (version 12.1, StataCorp) was used for the statistical analyses. Release number 4.00 of the GROUP data set was investigated. Missing AIMS, UPDRS, and PANSS items were replaced by mean scores of the nonmissing items when at most 1,3 , and 4 items were missing, respectively. We opted for this approach over multiple imputation because most of the scores on the DRMD scale items were zero, and we found that multiple imputation was too conservative even in patients with non-zero scores on the other items.

\section{Prevalence, Incidence, and Persistence}

Drug-related movement disorder prevalence, incidence, and persistence rates were determined and the individual rates for parkinsonism (bradykinesia, rigidity, and tremor), akathisia, tardive dyskinesia, and tardive dystonia. Prevalence rates were determined at baseline and at follow-up, and incidence rates were determined over this 3-year period. Persistence rates were defined as the percentage of patients that have a DRMD at baseline and follow-up of the total patients with a DRMD at baseline that were assessed at baseline and at follow-up.

\section{Clinical Correlates}

Multivariate regression models were used to identify potential correlates of DRMDs at baseline and at follow-up. Because ranges of scores on the UPDRS, BARS, and AIMS scales and the dystonia item vary, they were rescaled to a possible range of 0 to 100 to improve their comparability (eg, $C=A / B \times 100$, where 
$C$ is the rescaled score, $A$ is the observed score, and $B$ is the maximum range of the score). These 4 rescaled scores were regressed on a 4-level factor that distinguishes the 4 DRMD outcomes and a number of additional covariates/predictors, detailed below, and their interactions with the 4-level factor. Because the 4 DRMD scores were clustered within patients, we allowed residuals within patients to be correlated using an unstructured covariance matrix, also allowing residual variances to differ across the 4 outcomes. Using a multivariate model to analyze all 4 outcomes simultaneously allowed us to increase the power of the analysis by keeping the effect of several covariates constant over each DRMD outcome. In addition, we obtained information on the correlation between the DRMDs themselves (after accounting for the influence of any predictors in the model). The covariates set to interact with the 4-level factor (allowing the model to determine their respective associations with each individual DRMD) were age, ${ }^{3,20}$ ethnicity (Caucasian/other), ${ }^{21}$ prescribed antipsychotic dosage (DDD), ${ }^{22-24}$ PANSS score negative items, ${ }^{3,6}$ PANSS score positive items, ${ }^{3,20}$ and WAIS-III scale IQ score. ${ }^{25}$ The covariates and a priori confounders in the model set to have a constant effect over the DRMDs were $\operatorname{sex}^{22,25}$ and the number of prescribed antipsychotics, ${ }^{22}$ their type(s) (FGA/SGA/both), ${ }^{3}$ and method of administration (oral/depot)., ${ }^{3,22}$ The other covariates in the model were incidence and persistence rates, which were not compared among FGAs and SGAs because of the naturalistic design of the GROUP study and considering the 3 -year interval between assessments.

\section{RESULTS}

Sociodemographic and clinical characteristics of the patients who met the inclusion criteria are summarized in Table 1. Of the 1120 patients in the GROUP cohort, 828 patients completed at least 1 DRMD assessment and were eligible for inclusion in the prevalence, incidence, and persistence analyses. At the follow-up assessment, 447 patients were eligible for analysis. The primary reason for the high attrition rate was patients lost to follow-up. A test of proportion showed that the patients who were lost to follow-up after the baseline assessment had significantly more DRMDs $(z=-3.4, P<0.01)$. Most patients were around the age of 30 ; $96(12 \%)$ patients were younger than 20 years, $473(57 \%)$ patients were between 20 and 30 years, 199 (24\%) patients were between 30 and 40 years, and $52(6 \%)$ patients were older than 40 years. Table 2 lists the prevalence, 3 -year incidence and persistence rates of DRMDs, and most frequent combinations thereof. The prevalence and incidence rates were highest for parkinsonism followed by akathisia, and the most prevalent combination of DRMDs was having both parkinsonism and akathisia. Table 2 also lists the DRMDs persistence rates. Parkinsonism (especially bradykinesia) was the most persistent DRMD. A test of proportion showed that akathisia was significantly more prevalent in FGAs than SGAs at baseline $(22.4 \% / 9.9 \%, P<0.01)$; there were trends toward akathisia being more prevalent in FGAs at follow-up $(13.5 \% / 5.9 \%, P=0.08)$ and parkinsonism being more prevalent in FGAs at baseline (39.7\%/29.8\%, $P=0.08$ ). The prevalence of the other DRMDs did not differ significantly between patients treated with FGAs and SGAs. We also investigated the difference between the 2 most frequently prescribed SGAs olanzapine $(26 \% / 20 \%$ of patients at baseline/follow-up) and risperidone $(20 \% / 13 \%$ of patients at baseline/follow-up). There were no significant differences in the prevalence of DRMDs between patients treated with olanzapine or risperidone. Only a trend toward baseline akathisia being more prevalent in the patients treated with risperidone was observed $(13.1 \% / 7.5 \%, P=0.07)$.

Table 3 presents an overview of the clinical correlates at baseline and follow-up. Patients with a combined antipsychotic World Health Organization defined daily dose equivalent greater than five $(n=28)$ affected the mixed-effects model substantially and were excluded from the analysis, as their antipsychotic dose values were presumably incorrectly registered during their baseline and/ or follow-up interviews. A total of 630 patients completed all required assessments for the regression analyses at baseline and were investigated in the model, and 301 patients were investigated in the model of the follow-up data. The association between negative psychopathology symptoms (PANSS negative score) and parkinsonism (UPDRS score) was the only association significant at both baseline and follow-up, with patients scoring on average 0.41 [95\% confidence interval (CI), 0.31-0.51] and 0.35 (95\% CI, 0.18-0.52) points higher on the UPDRS for each 1-point increase on the PANSS negative scale. There was also a significant association between cognitive functioning (WAIS-III IQ scores) and parkinsonism:

TABLE 1. Sociodemographic and Clinical Characteristics at Baseline of Patients Having Completed a Movement Disorder Assessment

\begin{tabular}{|c|c|c|c|c|c|c|}
\hline & & & $\mathbf{n}$ & Mean (SD) & Range & $\%$ \\
\hline Age, y & & & 828 & $27(7)$ & $15-57$ & \\
\hline Sex $(\%$ male $)$ & & & 828 & & & 79 \\
\hline \multirow[t]{2}{*}{ Ethnicity } & Caucasian & & 828 & & & 78 \\
\hline & Other & & & & & 22 \\
\hline \multirow[t]{2}{*}{$D S M-I V$ classification } & Schizophrenia and related disorders & & 828 & & & 88 \\
\hline & Other nonaffective psychotic disorders & & & & & 12 \\
\hline Illness duration, $\mathrm{y}$ & & & 828 & $4(4)$ & $0-41$ & \\
\hline IQ (WAIS-III) & & & 794 & $94(15)$ & $57-140$ & \\
\hline \multirow[t]{3}{*}{ PANSS } & General (range, 16-112) & & 808 & $28(8)$ & $16-65$ & \\
\hline & Positive (range, $7-49$ ) & & 808 & $13(5)$ & $7-37$ & \\
\hline & Negative (range, 7-49) & & 803 & $14(6)$ & $7-38$ & \\
\hline \multirow[t]{6}{*}{ Antipsychotic } & Dose (DDD) & & 670 & $1.1(0.7)$ & $0.1-4.5$ & \\
\hline & Generation & FGA & 698 & & & 11 \\
\hline & & SGA & & & & 87 \\
\hline & & Both & & & & 2 \\
\hline & Depot (\% prescribed) & & 698 & & & 6 \\
\hline & $\%$ concomitant prescriptions of antich & nedication(s) & 828 & & & 6 \\
\hline
\end{tabular}


TABLE 2. Prevalence and Incidence of DRMDs and Combinations Thereof of All Patients and Patients On and Off Antipsychotic Treatment

\begin{tabular}{|c|c|c|c|c|c|c|c|c|}
\hline & \multicolumn{4}{|c|}{ Prevalence } & & & & \\
\hline & \multicolumn{2}{|c|}{ Baseline } & \multicolumn{2}{|c|}{ Follow-Up } & \multicolumn{2}{|c|}{ Incidence } & \multicolumn{2}{|c|}{ Persistence* } \\
\hline & $\mathbf{n}$ & $\%$ & $\mathbf{n}$ & $\%$ & $\mathbf{n}$ & $\%$ & $\mathbf{n}$ & $\%$ \\
\hline DRMDs & 828 & 39.3 & 447 & 36.5 & 249 & 24.5 & 148 & 54.7 \\
\hline Parkinsonism & 813 & 31.9 & 440 & 31.4 & 268 & 21.3 & 117 & 53.0 \\
\hline Tremor & 813 & 9.0 & 440 & 10.7 & 349 & 9.5 & 36 & 22.2 \\
\hline Rigidity & 813 & 6.3 & 440 & 5.2 & 366 & 4.6 & 19 & 10.5 \\
\hline Bradykinesia & 813 & 13.4 & 440 & 16.8 & 342 & 14.0 & 43 & 44.2 \\
\hline Akathisia & 820 & 11.0 & 446 & 7.2 & 356 & 5.1 & 35 & 17.1 \\
\hline Tardive dyskinesia & 821 & 3.7 & 446 & 3.6 & 383 & 3.1 & 10 & 20.0 \\
\hline Tardive dystonia & 813 & 1.5 & 447 & 1.8 & 384 & 1.6 & & \\
\hline Parkinsonism and akathisia & 806 & 5.5 & 439 & 3.0 & 242 & 1.2 & 13 & 7.7 \\
\hline Parkinsonism and tardive dyskinesia & 806 & 1.7 & 439 & 2.3 & 260 & 1.9 & & \\
\hline
\end{tabular}

This table only reports the combinations of DRMDs that are relatively prevalent $(>1.0 \%)$.

*Persistence was defined as the percentage of patients with a DRMD at both baseline and follow-up of all patients with a DRMD at baseline whom completed the follow-up assessment; this was only determined when at least 10 patients with a DRMD at baseline completed the follow-up assessment.

UPDRS scores were on average $0.66(95 \% \mathrm{CI}, 0.31-1.02)$ and $0.70(95 \% \mathrm{CI},-0.14$ to 1.26$)$ points lower for every 10 additional IQ points. However, this association was only significant at baseline. Table 4 reports the strengths of the correlations between the DRMDs at baseline and follow-up. Significant correlations were found between parkinsonism and akathisia, parkinsonism

TABLE 3. Multivariate Model Results: Regression Coefficients of the Correlates for Parkinsonism, Akathisia, Tardive Dyskinesia, and Tardive Dystonia Scores at Baseline $(n=630)$ and Follow-Up $(n=301)$

\begin{tabular}{|c|c|c|c|c|c|c|c|c|c|}
\hline \multirow[t]{2}{*}{$\begin{array}{l}\text { DIMD, Scale } \\
\text { (Total Range) }\end{array}$} & \multirow[t]{2}{*}{$\begin{array}{l}\text { Range in } \\
\text { Sample }\end{array}$} & \multicolumn{2}{|l|}{$\begin{array}{l}\text { Parkinsonism, } \\
\text { UPDRS (0-108) }\end{array}$} & \multicolumn{2}{|l|}{$\begin{array}{l}\text { Akathisia, } \\
\text { BARS (0-5) }\end{array}$} & \multicolumn{2}{|c|}{$\begin{array}{l}\text { Tardive Dyskinesia, } \\
\text { AIMS (0-28) }\end{array}$} & \multicolumn{2}{|c|}{$\begin{array}{l}\text { Tardive Dystonia, } \\
\text { Dystonia Item (0-4) }\end{array}$} \\
\hline & & $\beta(95 \% \mathrm{CI})$ & $P$ & $\beta(95 \% \mathrm{CI})$ & $P$ & $\beta(95 \% \mathrm{CI})$ & $P$ & $\beta(95 \%$ CI) & $P$ \\
\hline \multicolumn{10}{|l|}{ Baseline: } \\
\hline Age, y & $15-57$ & $.12(.04$ to .19$)$ & 0.002 & $-.00(-.01$ to .00$)$ & 0.308 & $.00(-.01$ to 0.2$)$ & 0.773 & $.00(-.00$ to .01$)$ & 0.311 \\
\hline Ethnicity (not Caucasian) & & $-.38(-1.65$ to .89$)$ & 0.559 & $.00(.15$ to .15$)$ & 0.987 & $-.14(-.39$ to .10$)$ & 0.258 & $0.00(-.07$ to .07$)$ & 0.943 \\
\hline $\begin{array}{l}\text { Antipsychotic dose } \\
\text { (DDD) }\end{array}$ & $0.1-4.5$ & $.07(-.73$ to .87$)$ & 0.865 & $-.04(-.13$ to .05$)$ & 0.422 & $.10(-.06$ to .26$)$ & 0.225 & $-.01(-.05$ to .04$)$ & 0.801 \\
\hline ymptoms & $7-37$ & $-.06(-.17$ to .04$)$ & 0.244 & $.02(.00$ to .03$)$ & 0.011 & $-.02(-.04$ to .00$)$ & 0.100 & $.00(-.00$ to .01$)$ & 0.189 \\
\hline ymptoms & $7-38$ & $.41(.31$ to .51$)$ & 0.000 & $.01(-.00$ to .02$)$ & 0.246 & $.03(.01$ to .05$)$ & 0.002 & $.00(-.00$ to .01$)$ & 0.416 \\
\hline IQ (WAIS-III)* & $57-146$ & $-.66(-1.02$ to -.31$)$ & 0.000 & $-.03(-.07$ & 0.180 & $-.01(-.08$ & 0.789 & $-.02(-.0$ & 0.064 \\
\hline \multicolumn{10}{|l|}{ Follow-up: } \\
\hline Age ( & $18-56$ & $.09(-.04$ & 0.167 & $.00(-.0$ & 0.694 & $-.00(-.03$ & 0.797 & $-.00(-$ & 0.775 \\
\hline Ethnicity (not Caucasian) & & $-.24(-2.24$ to 1.77$)$ & 0.818 & $-.00(-.18$ to .17$)$ & 0.956 & $.12(-.25$ to .50$)$ & 0.526 & $.04(-.08$ to .15$)$ & 0.518 \\
\hline $\begin{array}{l}\text { Antipsychotic dose } \\
\text { (DDD) }\end{array}$ & $0.0-5.0$ & -.08 (-1.09 to 0.93$)$ & 0.877 & $.02(-.06$ to .10$)$ & 0.665 & .15 (-.05 to .34$)$ & 0.137 & $.07(.02$ to .12$)$ & 0.012 \\
\hline $\begin{array}{l}\text { Positive symptoms } \\
\text { (PANSS) }\end{array}$ & $7-29$ & $.14(-.06$ to .33$)$ & 0.170 & $.03(.01$ to .04$)$ & 0.002 & $.04(.01$ to .08$)$ & 0.015 & $.01(-.00$ to .02$)$ & 0.138 \\
\hline $\begin{array}{l}\text { Negative symptoms } \\
\text { (PANSS) }\end{array}$ & $7-39$ & .35 (.18 to .52) & 0.000 & .00 (-.01 to .02$)$ & 0.844 & $.00(-.03$ to .04$)$ & 0.836 & $-.00(-.01$ to .01$)$ & 0.478 \\
\hline IQ (WAIS-III)* & $65-146$ & $-.70(-1.26$ to -.14$)$ & 0.014 & $.01(-.04$ to .06$)$ & 0.741 & $-.04(-.15$ to .06$)$ & 0.412 & $-.00(-.03$ to .03$)$ & 0.970 \\
\hline \multicolumn{10}{|c|}{$\begin{array}{l}\text { The } \beta \text { coefficients and CIs in this table represent changes on the respective DRMD scales (ie, on average a 10-year older patient scores } 1.2 \text { point higher } \\
\text { on the UPDRS assuming the patients' other independent variables are comparable). The reported independent variables were corrected for the a priori con- } \\
\text { founders sex and the number of prescribed antipsychotics, their generation (FGA/SGA/both), and method of administration (oral/depot). We found that pre- } \\
\text { scribing multiple antipsychotics significantly increased the severity of DRMDs }(P=0.003) \text {; this was found only at the follow-up assessment. Coefficients in } \\
\text { bold are considered significant }(P<0.010) \text {. }\end{array}$} \\
\hline *Average difference in & D & per 10 u points & & & & & & & \\
\hline
\end{tabular}


TABLE 4. Baseline and Follow-Up Pearson Correlation Coefficients Between DRMDs and the Respective Correlation Coefficients Adjusted for the Independent Variables in the Regression Model

\begin{tabular}{|c|c|c|c|c|c|c|}
\hline & \multicolumn{2}{|c|}{ Parkinsonism } & \multicolumn{2}{|c|}{ Akathisia } & \multicolumn{2}{|c|}{ Tardive Dyskinesia } \\
\hline & Pearson & Adjusted & Pearson & Adjusted & Pearson & Adjusted \\
\hline \multicolumn{7}{|c|}{ Parkinsonism (UPDRS) } \\
\hline \multicolumn{7}{|l|}{ Baseline } \\
\hline \multicolumn{7}{|l|}{ Follow-up } \\
\hline \multicolumn{7}{|c|}{ Akathisia (BARS) } \\
\hline Baseline & 0.22 & 0.19 & & & & \\
\hline Follow-up & 0.12 & 0.07 & & & & \\
\hline \multicolumn{7}{|c|}{ Tardive dyskinesia (AIMS) } \\
\hline Baseline & 0.18 & 0.14 & 0.11 & 0.10 & & \\
\hline Follow-up & 0.31 & 0.27 & 0.20 & 0.18 & & \\
\hline \multicolumn{7}{|c|}{ Tardive dystonia } \\
\hline Baseline & 0.07 & 0.03 & 0.03 & 0.00 & 0.02 & 0.03 \\
\hline Follow-up & 0.04 & 0.02 & 0.12 & 0.12 & 0.11 & 0.07 \\
\hline
\end{tabular}

and tardive dyskinesia, and akathisia and tardive dyskinesia. These correlations remained significant after correcting for the confounding variables in the regression models.

\section{DISCUSSION}

This study shows that the prevalence and incidence rates of DRMDs can be high even in a relatively young population predominately treated with SGAs. This stands in contrast with the idea that SGAs are associated with low DRMD incidence and prevalence rates. At baseline and follow-up, the DRMD prevalence rates of the GROUP cohort were $39.3 \%$ and $36.5 \%$, respectively, and the incidence rate was $24.5 \%$. Parkinsonism was the most common DRMD with an incidence rate of $21.3 \%$ and prevalence rates of $31.9 \%$ and $31.4 \%$ at baseline and follow-up. Parkinsonism was also the most persistent DRMD, persisting over baseline and follow-up in $53.0 \%$ of the patients.

\section{Prevalence Rates}

The baseline prevalence rates of DRMDs in the GROUP cohort were remarkably high (39.3\%). This could be of substantial clinical impact as DRMDs are known to cause discomfort in affected individuals ${ }^{1}$ and may affect functioning in daily life and contribute to noncompliance of antipsychotic treatment. ${ }^{2}$ The 3 -year follow-up data also show high prevalence rates of DRMDs $(36.5 \%)$. With a test of proportions, we found that only the prevalence of akathisia is slightly but significantly lower at the 3-year follow-up. This study's DRMD prevalence rates are in line with the reports of the EUFEST study, which investigated patients with similar characteristics. ${ }^{89}$ However, this study did report a lower prevalence rate for parkinsonism (11\%) compared with our findings $(31 \%-32 \%)$. This discrepancy could be caused by the recruitment of antipsychotic-naive patients in their baseline sample and the higher prescription rate of anticholinergic medication in their study. Another recent study reported even lower prevalence rates for parkinsonism $(2 \%)$ and akathisia $(1 \%)$ in a population 7 years younger. ${ }^{5}$ This is unexpected as the poor prognosis of individuals with an early onset of schizophrenia ${ }^{26}$ might also suggest an increased risk for DRMDs. Nevertheless, these authors did find high prevalence rates of subclinical parkinsonism (26\%) and akathisia
$(12 \%){ }^{5}$ It could be that the rating scale they used (Simpson Angus Scale) is less sensitive for detecting parkinsonism than the rating scale (UPDRS) used in our study. ${ }^{27}$ However, this alone cannot account for the difference in prevalence of parkinsonism with our study. In summary, our findings show that DRMDs prevalence rates are high even in relatively young patients with relatively brief exposure to predominately SGA treatment.

\section{Incidence}

One in 4 patients without a DRMD at baseline had a DRMD at 3-year follow-up, and together with the high prevalence of DRMDs at baseline, this finding indicates that most of the patients in the GROUP study have had a DRMD at some point in time. Besides being the most prevalent DRMD, parkinsonism also had the highest incidence. A few other studies reported similar DRMD incidence rates for parkinsonism (22\%), akathisia (4\%), and extrapyramidal symptoms $(15 \%-30 \%))^{3,23,28-30}$ However, these studies investigated populations with an increased risk of DRMDs (especially parkinsonism) as their patients were considerably older on average $^{23}$ and predominately treated with FGAs. ${ }^{3,25}$ We therefore expected our sample to have lower DRMD incidence rates but found that DRMDs incident rates in relatively young patients are remarkably high.

The low incidence of tardive DRMDs in this study was in line with our expectations, as the risk of developing a tardive DRMD increases with the cumulative exposure to antipsychotics. ${ }^{31}$ The cumulative exposure to antipsychotics was modest in the sample we studied. The clinical implications of developing a tardive DRMD can be substantial, as significant associations between tardive dyskinesia, dopamine supersensitivity psychosis, and treatmentresistant schizophrenia have been reported. ${ }^{32}$ A meta-analysis of 11 studies comparing incidence rates of tardive dyskinesia reported a mean annual incidence of $2.1 \%,{ }^{28}$ which is similar to our study (3.1\%). The incidence of tardive dystonia was in line with previous reports $(0 \%-0.7 \%))^{23,30}$ Overall, the high incidence rates we found indicate that DRMDs are a considerable problem that most patients are likely to experience during the first years of their antipsychotic treatment. 


\section{Persistence}

In this study, persistence was defined as having a DRMD at baseline and at follow-up. Persistence is a measure to determine the extent of the burden caused by DRMDs. This study shows that more than half of the patients with parkinsonism at baseline also suffered from parkinsonism at follow-up. Few other studies reported persistence rates. When reported, persistence rates of extrapyramidal symptoms $(81 \%),{ }^{29}$ parkinsonism $(56 \%),{ }^{33}$ akathisia $(5 \%-67 \%),{ }^{33}$ and tardive dyskinesia $(28 \%-80 \%)^{29,33}$ vary substantially. These studies differ from the current study as they investigated older patients on long-term antipsychotic treatment and assessed DRMDs more frequently and on shorter intervals. ${ }^{29,33}$ Therefore, it was expected that this study's persistence rates would be lower, as the chance of a DRMD persisting over this study's 3-year follow-up period is lower in comparison to the other studies' shorter measurement intervals. Although the persistence rates for parkinsonism (53\%), akathisia (17\%), and tardive dyskinesia $(20 \%)$ determined in our study are slightly lower than the previously reported rates, they are still quite high when taken into account that our study sample is significantly younger and was predominately treated with SGAs for a relatively brief period.

\section{Drug-Related Movement Disorder Correlates}

The large sample and wide range of outcomes investigated in this study offered us the opportunity to investigate the associations between DRMDs and potential correlates. The strongest associations that were found in this study were the interrelationships between DRMDs. Parkinsonism and tardive dyskinesia, and akathisia and tardive dyskinesia were significantly correlated at baseline and follow-up even when we adjusted for the effects of confounders. At baseline there was also a significant correlation between parkinsonism and akathisia. Previous studies have also reported that extrapyramidal symptoms ${ }^{3,21}$ (akathisia and parkinsonism $^{20}$ ) and tardive dyskinesia are interrelated. Our model also confirms that parkinsonism is significantly associated with age, IQ, and negative symptoms. ${ }^{3,6,25}$ However, the association that we found between age and severity of parkinsonism was relatively weak. On average, a 10-year older patient only scored 1.2 more points on the UPDRS. As the association between parkinsonism and age is much stronger in older populations, ${ }^{3,23}$ we believe the risk for parkinsonism increases nonlinearly with age. Interestingly, we found that parkinsonism, IQ, and negative symptoms were significantly associated with each other and seem to be interrelated. Several other studies have also reported significant correlations between parkinsonism and cognitive deficits, ${ }^{6,25}$ parkinsonism and negative symptoms, ${ }^{6}$ and cognitive deficits and negative symptoms. ${ }^{34}$ The interrelationship between motor, cognitive, and negative symptoms supports the theory that these symptoms are integral symptoms of schizophrenia and other psychotic disorders, as proposed in the neurodevelopmental hypothesis. ${ }^{35}$ This hypothesis is further supported by studies that have shown that cognitive, motor, and social impairment are common in individuals destined to develop schizophrenia, ${ }^{35}$ and other studies reporting that functional outcome and response to treatment are associated with increased severity of cognitive, ${ }^{36}$ motor, ${ }^{37}$ and negative symptoms. ${ }^{38}$ Therefore, regularly assessing DRMDs can improve the accuracy of the diagnosis, which may result in a better prognosis of schizophrenia. Nevertheless, akathisia and tardive dyskine$\operatorname{sia}^{20}$ were only weakly associated with psychopathology in this study, and they were not associated with IQ. This suggests that, in contrast to parkinsonism, akathisia and tardive dyskinesia are not interrelated with cognitive functioning and psychopathology, and the conflicting reports by other studies support this. ${ }^{20,24,39}$ Several studies have reported an association between antipsychotic treatment and severity of DRMDs. ${ }^{3,20,23}$ We did not find any significant associations between severity of DRMDs and antipsychotic treatment with our model. An explanation could be that relevant changes in antipsychotic treatment in response to DRMDs were not recorded by this study. As this study used a naturalistic design and we only recorded the current antipsychotic treatment at baseline and at 3-year follow-up, changes in antipsychotic treatments before baseline or between baseline and follow-up were not recorded. However, when confounders were not controlled for, opposed to the regression models, we did find that akathisia was significantly more prevalent in patients treated with FGAs than SGAs. In addition, akathisia was almost significantly more prevalent in the patients treated with risperidone as opposed to the patients treated with olanzapine. The low prevalence of akathisia in patients treated with olanzapine is in accordance with a previous study. ${ }^{8}$ Findings of previous studies on the relation between sex and DRMDs are conflicting. ${ }^{3-5,21,23}$ Our model did not find an association between sex and DRMDs; therefore, we think it is unlikely that the association between sex and DRMDs is strong. Overall, these associations underline the diagnostic and prognostic value of DRMDs, which may have been overlooked, especially considering that tardive dyskinesia has been associated with dopamine supersensitivity psychosis and treatment-resistant schizophrenia $^{32}$ and that subtle spontaneous DRMDs are present in individuals at ultrahigh risk for psychosis ${ }^{40}$ and family members of patients with schizophrenia. ${ }^{19}$

\section{Strengths and Limitations}

This is one of few studies to investigate DRMDs in a large sample of relatively young patients a few years after onset of psychosis. It enabled us to assess DRMDs with minimal confounding by extended and diverse prior antipsychotic and other treatments. Furthermore, the large size of the investigated cohort and the use of specific (valid and reliable) rating scales for each DRMD and the fact that we assessed not only prevalence but also incidence and persistence of DRMDs are the most important strengths of this study. These aspects greatly benefit the generalizability of our findings. IN addition, they provided us with enough statistical power to investigate the associations of DRMDs with a wide range of clinical and sociodemographical factors.

It is likely that the incidence, persistence rates, and the prevalence rates at follow-up were even higher than the figures we reported, as the DRMD baseline prevalence rates for the group of patients that were lost to follow-up after the baseline assessment were significantly higher than those of the patients that also completed the follow-up assessment.

A limitation of this study was that the time window between baseline and follow-up (3 years) may have been too broad to detect all relevant fluctuations of DRMDs, antipsychotic treatment, and psychopathology. Considering that the incidence and persistence rates were determined by data from these 2 time points, and not by cumulative data, we think that the rates we found may even have been an underestimation. Furthermore, the naturalistic design of this study may have also limited the possibility to investigate associations between treatment and DRMDs, as treatment may have been altered because of DRMDs.

\section{CONCLUSIONS AND CLINICAL IMPLICATIONS}

This study shows that DRMDs occur frequently in relatively young patients predominately on SGA treatment. The high incidence and persistence rates result in many patients having DRMDs merely a couple of years after developing psychosis. This is concerning as DRMDs have a substantial negative impact on the quality of life of these patients. This underscores the importance 
of accurate monitoring of DRMDs even in the early years of treatment of psychotic syndromes. Furthermore, to some extent, DRMDs may be of prognostic and diagnostic value for schizophrenia and other psychotic disorders, as they have been related to psychopathology and cognitive functioning, which has been confirmed by our findings. Furthermore, they also share a similar underlying neuropathology, and movement disorders occur in antipsychoticnaive patients as well. Therefore, we recommend future studies to explore the use of movement disorders for the diagnosis and prognosis of psychotic disorders.

\section{ACKNOWLEDGMENTS}

The authors are grateful for the generosity of time and effort by the patients and their families, healthy subjects, and all researchers who make this GROUP project possible.

\section{AUTHOR DISCLOSURE INFORMATION}

The authors declare no conflicts of interest.

\section{REFERENCES}

1. Fujimaki K, Morinobu S, Yamashita H, et al. Predictors of quality of life in inpatients with schizophrenia. Psychiatry Res. 2012;197: 199-205.

2. Fenton WS, Blyler CR, Heinssen RK. Determinants of medication compliance in schizophrenia: empirical and clinical findings. Schizophr Bull. 1997;23:637-651.

3. Novick D, Haro JM, Bertsch J, et al. Incidence of extrapyramidal symptoms and tardive dyskinesia in schizophrenia: thirty-six-month results from the European schizophrenia outpatient health outcomes study. J Clin Psychopharmacol. 2010;30:531-540.

4. van Harten PN, Matroos GE, Hoek HW, et al. The prevalence of tardive dystonia, tardive dyskinesia, parkinsonism and akathisia The Curacao Extrapyramidal Syndromes Study: I. Schizophr Res. 1996;19:195-203.

5. Gebhardt S, Härtling F, Hanke M, et al. Prevalence of movement disorders in adolescent patients with schizophrenia and in relationship to predominantly atypical antipsychotic treatment. Eur Child Adolesc Psychiatry. 2006; 15:371-382.

6. Byne W, Stamu C, White L, et al. Prevalence and correlates of parkinsonism in an institutionalized population of geriatric patients with chronic schizophrenia. Int J Geriatr Psychiatry. 2000;15:7-13.

7. Glazer WM. Review of incidence studies of tardive dyskinesia associated with typical antipsychotics. J Clin Psychiatry. 2000;61(suppl 4):15-20.

8. Kahn RS, Fleischhacker WW, Boter H, et al. Effectiveness of antipsychotic drugs in first-episode schizophrenia and schizophreniform disorder: an open randomised clinical trial. Lancet. 2008;371:1085-1097.

9. Rybakowski JK, Vansteelandt K, Remlinger-Molenda A, et al. Extrapyramidal symptoms during treatment of first schizophrenia episode: results from EUFEST. Eur Neuropsychopharmacol. 2014;24:1500-1505.

10. Korver N, Quee PJ, Boos HB, et al. Genetic Risk and Outcome of Psychosis (GROUP), a multi-site longitudinal cohort study focused on gene-environment interaction: objectives, sample characteristics, recruitment and assessment methods. Int J Methods Psychiatr Res. 2012; 21:205-221.

11. van Winkel R. Family-based analysis of genetic variation underlying psychosis-inducing effects of cannabis: sibling analysis and proband follow-up. Arch Gen Psychiatry. 2011;68:148-157.

12. Andreasen NC, Flaum M, Arndt S. The Comprehensive Assessment of Symptoms and History (CASH). An instrument for assessing diagnosis and psychopathology. Arch Gen Psychiatry. 1992;49:615-623.

13. Wing JK, Babor T, Brugha T, et al. SCAN. Schedules for clinical assessment in neuropsychiatry. Arch Gen Psychiatry. 1990;47:589-593.
14. Kay SR, Fiszbein A, Opler LA. The positive and negative syndrome scale (PANSS) for schizophrenia. Schizophr Bull. 1987;13:261-276.

15. Wechsler D. WAIS-III Administration and Scoring Manual. San Antonio, TX: The Psychological Corporation; 1997.

16. Martínez-Martín P, Gil-Nagel A, Gracia LM, et al. Unified Parkinson's Disease Rating Scale characteristics and structure. The Cooperative Multicentric Group. Mov Disord. 1994;9:76-83.

17. Barnes TR. A rating scale for drug-induced akathisia. Br J Psychiatry. 1989;154:672-676.

18. Guy WA. Abnormal Involuntary Movement Scale (AIMS). In: Guy WA, ed. EDCEU Assessment Manual for Psychopharmacology. Washington, DC: Department of Health Education and Welfare; 1976:534-537.

19. Koning JP, Kahn RS, Tenback DE, et al. Movement disorders in nonpsychotic siblings of patients with nonaffective psychosis. Psychiatry Res. 2011;188:133-137.

20. Miller DD, McEvoy JP, Davis SM, et al. Clinical correlates of tardive dyskinesia in schizophrenia: baseline data from the CATIE schizophrenia trial. Schizophr Res. 2005;80:33-43.

21. Tenback DE, van Harten PN, van Os J. Non-therapeutic risk factors for onset of tardive dyskinesia in schizophrenia: a meta-analysis. Mov Disord. 2009;24:2309-2315.

22. Chen JJ, Swope DM. Movement disorders. In: Tisdale JE, Miller DA, eds. Drug-Induced Diseases: Prevention, Detection, and Management. 2nd ed. Bethesda, MD: American Society of Health-System Pharmacists; 2010: 211-235

23. Bakker PR, de Groot IW, van Os J, et al. Predicting the incidence of antipsychotic-induced movement disorders in long-stay patients: a prospective study. Epidemiol Psychiatr Sci. 2013;22:375-379.

24. Matson JL, Fodstad JC, Neal D, et al. Risk factors for tardive dyskinesia in adults with intellectual disability, comorbid psychopathology, and long-term psychotropic use. Res Dev Disabil. 2010;31:108-116.

25. Thanvi B, Treadwell S. Drug induced parkinsonism: a common cause of parkinsonism in older people. Postgrad Med J. 2009;85:322-326.

26. Clemmensen L, Vernal DL, Steinhausen HC. A systematic review of the long-term outcome of early onset schizophrenia. BMC Psychiatry. 2012; $12: 150$

27. Knol W, Keijsers CJ, Jansen PA, et al. Systematic evaluation of rating scales for drug-induced parkinsonism and recommendations for future research. J Clin Psychopharmacol. 2010;30:57-63.

28. Correll CU, Leucht S, Kane JM. Lower risk for tardive dyskinesia associated with second-generation antipsychotics: a systematic review of 1-year studies. Am J Psychiatry. 2004;161:414 425.

29. Tenback DE, van Harten PN, Slooff CJ, et al. Incidence and persistence of tardive dyskinesia and extrapyramidal symptoms in schizophrenia. J Psychopharmacol. 2010;24:1031-1035.

30. van Harten PN, Hoek HW, Matroos GE, et al. Incidence of tardive dyskinesia and tardive dystonia in African Caribbean patients on long-term antipsychotic treatment: the Curaçao extrapyramidal syndromes study V. J Clin Psychiatry. 2006;67:1920-1927.

31. Tarsy D, Baldessarini RJ. Epidemiology of tardive dyskinesia: is risk declining with modern antipsychotics? Mov Disord. 2006;21: 589-598.

32. Suzuki T, Kanahara N, Yamanaka H, et al. Dopamine supersensitivity psychosis as a pivotal factor in treatment-resistant schizophrenia. Psychiatry Res. 2015;227:278-282.

33. Bakker PR, de Groot IW, van Os J, et al. Long-stay psychiatric patients: a prospective study revealing persistent antipsychotic-induced movement disorder. PLoS One. 2011;6:e25588.

34. Harvey PD, Koren D, Reichenberg A, et al. Negative symptoms and cognitive deficits: what is the nature of their relationship? Schizophr Bull. 2006;32:250-258. 
35. Howes OD, Murray RM. Schizophrenia: an integrated sociodevelopmental-cognitive model. Lancet. 2014;383:1677-1687.

36. Jakubovski E, Carlson JP, Bloch MH. Prognostic subgroups for remission, response, and treatment continuation in the Clinical Antipsychotic Trials of Intervention Effectiveness (CATIE) trial. J Clin Psychiatry. 2015;76: 1535-1545

37. Chen L, Ascher-Svanum H, Lawson A, et al. Movement disorder profile and treatment outcomes in a one-year study of patients with schizophrenia. Neuropsychiatr Dis Treat. 2013;9:815-822.
38. Fervaha G, Foussias G, Agid O, et al. Impact of primary negative symptoms on functional outcomes in schizophrenia. Eur Psychiatry. 2014;29: 449-455.

39. Kim JH, Byun HJ. Association of subjective cognitive dysfunction with akathisia in patients receiving stable doses of risperidone or haloperidol. J Clin Pharm Ther. 2007;32:461-467.

40. Mittal VA, Daley M, Shiode MF, et al. Striatal volumes and dyskinetic movements in youth at high-risk for psychosis. Schizophr Res. 2010;123: $68-70$. 